\title{
HARMONY 4: randomised clinical trial comparing once-weekly albiglutide and insulin glargine in patients with type 2 diabetes inadequately controlled with metformin with or without sulfonylurea
}

\author{
Peter N. Weissman • Molly C. Carr • June Ye • \\ Deborah T. Cirkel • Murray Stewart • Caroline Perry • \\ Richard Pratley
}

Received: 7 May 2014 / Accepted: 23 July 2014 /Published online: 11 September 2014

(C) Springer-Verlag Berlin Heidelberg 2014

\begin{abstract}
Aims/hypothesis The aim of this study was to compare the efficacy and safety of once-weekly albiglutide with once-daily insulin glargine (A21Gly,B31Arg,B32Arg human insulin) in patients with type 2 diabetes inadequately controlled on metformin with or without sulfonylurea.

Methods This was a randomised, open-label, multicentre $(n=222)$, parallel-group, non-inferiority out-patient clinical trial, with 779 patients enrolled in the study. The study was conducted in 222 centres located in four countries. Patients aged $\geq 18$ years with type 2 diabetes treated with metformin ( \pm sulfonylurea) for at least 3 months with a baseline $\mathrm{HbA}_{1 \mathrm{c}}$ $7.0-10.0 \%(53.0-85.8 \mathrm{mmol} / \mathrm{mol})$ were randomly assigned (2:1) via a computer-generated randomisation sequence with a voice response system to receive albiglutide (30 $\mathrm{mg}$ once a week, $n=504$ ) or insulin glargine (10 U once a day, $n=241$ ) added to current therapy. Participants and investigators were not masked to treatment assignment. Doses of each
\end{abstract}

Electronic supplementary material The online version of this article (doi:10.1007/s00125-014-3360-3) contains peer-reviewed but unedited supplementary material, which is available to authorised users.

P. N. Weissman $(\bowtie)$

Endocrinology Associates, 7867 N Kendall Dr \#80, Miami,

FL 33156, USA

e-mail: peternweissman@att.net

M. C. Carr · J. Ye $\cdot$ M. Stewart $\cdot$ C. Perry

GlaxoSmithKline, Upper Merion, PA, USA

D. T. Cirkel

GlaxoSmithKline, Stevenage, Herts, UK

R. Pratley

Florida Hospital Diabetes Institute, Translational Research Institute for Metabolism and Diabetes, Sanford-Burnham Medical Research, Orlando, FL, USA medication were adjusted on the basis of the glycaemic response. The primary endpoint was change from baseline in $\mathrm{HbA}_{1 \mathrm{c}}$ at week 52 .

Results In the albiglutide group, $\mathrm{HbA}_{1 \mathrm{c}}$ declined from $8.28 \pm$ $0.90 \%(67.0 \pm 9.8 \mathrm{mmol} / \mathrm{mol})(\mathrm{mean} \pm \mathrm{SD})$ at baseline to $7.62 \pm$ $1.12 \%(59.8 \pm 12.2 \mathrm{mmol} / \mathrm{mol})$ at week 52 . A similar reduction occurred in the insulin glargine group $(8.36 \pm 0.95 \%$ to $7.55 \pm$ $1.04 \%$ [ $67.9 \pm 10.4$ to $59.0 \pm 11.4 \mathrm{mmol} / \mathrm{mol}])$. The modeladjusted treatment difference of $0.11 \%(95 \% \mathrm{CI}-0.04 \%$, $0.27 \%)(1.2 \mathrm{mmol} / \mathrm{mol}[95 \% \mathrm{CI}-0.4,3.0 \mathrm{mmol} / \mathrm{mol}])$ indicated non-inferiority of albiglutide to insulin glargine based on the pre-specified non-inferiority margin of $0.3 \%(3.3 \mathrm{mmol} / \mathrm{mol}$, $p=0.0086$ ). Body weight increased in the insulin glargine group and decreased in the albiglutide group, with a mean treatment difference of $-2.61 \mathrm{~kg}(95 \% \mathrm{CI}-3.20,-2.02 ; p<0.0001)$. Documented symptomatic hypoglycaemia occurred in a higher proportion of patients in the insulin glargine group than in the albiglutide group ( $27.4 \%$ vs $17.5 \%, p=0.0377)$.

Conclusions/interpretation Albiglutide was non-inferior to insulin glargine at reducing $\mathrm{HbA}_{1 \mathrm{c}}$ at week 52, with modest weight loss and less hypoglycaemia. Both drugs were well tolerated. Albiglutide may be considered an alternative to insulin glargine in this patient population.

Trial registration: ClinicalTrials.gov NCT00838916 (completed)

Funding: This study was planned and conducted by GlaxoSmithKline.

Keywords Albiglutide · GLP-1 agonist · Insulin glargine · Type 2 diabetes
Abbreviations
AE Adverse event
DPP-4 Dipeptidyl peptidase-4 


$\begin{array}{ll}\text { FPG } & \text { Fasting plasma glucose } \\ \text { GLP-1 } & \text { Glucagon-like peptide 1 } \\ \text { ISR } & \text { Injection-site reaction } \\ \text { ITT } & \text { Intent-to-treat } \\ \text { LOCF } & \text { Last observation carried forward } \\ \text { LS } & \text { Least squares } \\ \text { PAC } & \text { Pancreatitis Adjudication Committee } \\ \text { SAE } & \text { Serious adverse event } \\ \text { SU } & \text { Sulfonylurea }\end{array}$

\section{Introduction}

Type 2 diabetes is a progressive disease characterised by worsening beta cell function over time. Although patients respond well to lifestyle changes and initiation of monotherapy with oral antihyperglycaemic agents (usually metformin) to control blood glucose, most of them will require higher doses and additional agents in an effort to achieve glycaemic targets [1]. Eventually, many patients will require the addition of insulin to their treatment regimen to maintain glycaemic control [2]. Long-acting, or basal insulin, which is dosed once a day and provides relatively constant blood levels over $24 \mathrm{~h}$, is typically the first type of insulin added to the treatment regimen [2]. As is true with other forms of insulin, the use of basal insulin is associated with weight gain and hypoglycaemia [3, 4]. Hypoglycaemia and weight gain are factors that influence tolerability and compliance of insulin therapy in type 2 diabetes [5,6]. Agents that lower glucose levels and lead to weight loss/weight neutrality with a low hypoglycaemic potential may be preferable alternatives to insulin. Injectable glucagonlike peptide-1 (GLP-1) receptor agonists have been shown in clinical trials to improve glycaemic control by stimulating insulin secretion in a glucose-dependent fashion, suppressing glucagon output, and inducing satiety, leading to weight loss $[7,8]$.

Albiglutide (GlaxoSmithKline, Collegeville, PA, USA) is a novel, once-weekly, long-acting GLP-1 receptor agonist composed of a dipeptidyl peptidase-4 (DPP-4)-resistant GLP-1 dimer linked to recombinant human albumin. This modification extends the half-life to $\sim 5$ days and allows weekly dosing $[9,10]$. Limited data exist that directly compare basal insulin with non-insulin treatments for diabetes. We report the 1 year results (primary endpoint) of a 3 year phase 3 clinical study comparing weekly albiglutide with daily doses of the basal insulin, insulin glargine (A21Gly,B31 Arg,B32Arg human insulin; sanofi-aventis US, Bridgewater, NJ, USA), added to the treatment regimen of patients with type 2 diabetes inadequately controlled by metformin with or without sulfonylurea (SU).

\section{Methods}

Study design This phase 3 study was a 3 year, randomised, open-label, parallel-group multicentre clinical trial designed to evaluate the efficacy and safety of weekly subcutaneous doses of albiglutide compared with daily subcutaneous doses of insulin glargine in patients with type 2 diabetes. The primary endpoint was change from baseline in $\mathrm{HbA}_{1 \mathrm{c}}$ at week 52 . Patients were $\geq 18$ years with type 2 diabetes inadequately controlled on their current regimen of metformin alone or metformin + SU. Metformin $( \pm \mathrm{SU})$ must have been taken for at least 3 months with a stable dose of metformin $\geq 1,500 \mathrm{mg}$ (or maximum tolerated dose) for $\geq 8$ weeks before randomisation. Other inclusion criteria included a BMI of $20-45 \mathrm{~kg} / \mathrm{m}^{2}$, baseline $\mathrm{HbA}_{1 \mathrm{c}} 7.0-10.0 \%$ (53.0-85.8 mmol/ $\mathrm{mol}$ ), estimated creatinine clearance $>60 \mathrm{ml} / \mathrm{min}$, and fasting C-peptide $\geq 0.8 \mathrm{ng} / \mathrm{ml}$. Important exclusion criteria included a history of cancer, treated diabetic gastroparesis, current symptomatic biliary disease or history of pancreatitis, significant gastrointestinal surgery, or recent significant cardiovascular (within 2 months) or cerebrovascular (within 1 month) events and history or family history of medullary carcinoma or multiple endocrine neoplasia type 2. Patients who met additional exclusion criteria, including elevated levels of total bilirubin, alanine aminotransferase, aspartate aminotransferase, amylase, lipase or fasting triacylglycerol, were also excluded.

The study comprised four periods: screening, 4 weeks of placebo run-in, treatment period (52 weeks of treatment to assess the primary endpoint followed by a further 104 weeks of treatment), and 8 weeks of follow-up. Patients were randomised in a 2:1 ratio to subcutaneous albiglutide $30 \mathrm{mg}$ once a week or daily subcutaneous injections of insulin glargine starting at $10 \mathrm{U}$. Randomisation was by a sequestered fixed schedule (electronic supplementary material [ESM] Methods) and was stratified by $\mathrm{HbA}_{1 \mathrm{c}}$ level $(<8.0 \%$ vs $\geq 8.0 \%[<63.9 \mathrm{vs} \geq 63.9 \mathrm{mmol} / \mathrm{mol}])$, age ( $<65 \mathrm{vs} \geq 65$ years), history of myocardial infarction (yes vs no), and current glucose-lowering treatment (metformin alone vs metformin + SU). Patients remained on their current background glucoselowering treatment regimen throughout the trial, except that, in the event of severe or recurrent hypoglycaemia, the dose of SU could be reduced or discontinued.

After starting treatment, patients who experienced persistent hyperglycaemia qualified to undergo dose uptitration and hyperglycaemia rescue. In the albiglutide arm, the dose could be uptitrated to $50 \mathrm{mg}$ once a week after week 4 based on the glycaemic criteria described in ESM Table 1. Dose adjustments in the insulin glargine arm were made weekly based on the mean of the 2 previous day's self-monitored glucose results. The dose was increased if the fasting plasma glucose (FPG) was $\geq 5.6 \mathrm{mmol} / \mathrm{l}(100 \mathrm{mg} / \mathrm{dl})$ provided that there was no documented hypoglycaemia in the preceding week (further 
details are provided in ESM Table 2). After uptitration, patients reaching predefined FPG or $\mathrm{HbA}_{1 \mathrm{c}}$ thresholds in either treatment arm could receive hyperglycaemic rescue therapy (i.e. the addition of further glucose-lowering medication; see ESM Tables 1 and 3) in addition to study medication and remain in the study. Once a patient met the predefined laboratory criteria for rescue, the choice of rescue medication was determined by the investigator (see ESM List of Study Investigators) and may have included more intensive insulin titration or the addition of other glucose-lowering medications. Use of other GLP-1 analogues as rescue was prohibited, and use of DPP-4 inhibitors was discouraged. Blood samples for albiglutide pharmacokinetic assessment were collected as described in ESM Methods.

Safety The safety population comprised all randomised patients who received at least one dose of study medication. Safety endpoints over time included evaluations of adverse events (AEs) and serious AEs (SAEs), safety events of special interest, clinical laboratory variables, vital sign measurements, ECG readings, physical examinations and immunogenicity. Blood samples for immunogenicity testing were taken at nine time points throughout the study; results will be reported separately as part of the final (3 year) study. All major adverse cardiovascular events and potential events of pancreatitis were adjudicated by an independent, blinded Clinical Endpoint Committee and Pancreatitis Adjudication Committee (PAC), respectively (see ESM Methods for PAC methods). Cardiovascular events will be reported separately as part of a metaanalysis. Hypoglycaemia severity was defined according to the ADA criteria [11].

Statistical analysis The primary efficacy endpoint was change from baseline in $\mathrm{HbA}_{1 \mathrm{c}}$ at week 52 in the intent-to-treat (ITT) population, which included all randomised patients who received $\geq 1$ dose of study medication and had both a baseline and $\geq 1$ post-baseline assessments of $\mathrm{HbA}_{1 \mathrm{c}}$. Secondary efficacy endpoints included change from baseline in FPG at week 52, changes from baseline in $\mathrm{HbA}_{1 \mathrm{c}}$ and FPG over time, time to hyperglycaemic rescue, proportion of patients achieving $\mathrm{HbA}_{1 \mathrm{c}}<6.5 \%(<47.5 \mathrm{mmol} / \mathrm{mol}),<7.0 \%$ ( $\left.<53.0 \mathrm{mmol} / \mathrm{mol}\right)$ and $<7.5 \%$ ( $<58.5 \mathrm{mmol} / \mathrm{mol})$, change in body weight over time, and population pharmacokinetics of albiglutide.

With a planned enrolment of 225 patients in the insulin glargine group and 450 patients in the albiglutide group, the study had $\geq 92 \%$ power to demonstrate non-inferiority of albiglutide vs insulin glargine for $\mathrm{HbA}_{1 \mathrm{c}}$ change from baseline to week 52, assuming a non-inferiority limit of $0.3 \%$ (3.3 $\mathrm{mmol} / \mathrm{mol})$. In general, last observation carried forward (LOCF) was used for all efficacy endpoints. Patients who withdrew from the study for any reason had their last postbaseline $\mathrm{HbA}_{1 \mathrm{c}}$ observation carried forward, and patients who received hyperglycaemic rescue therapy had their latest pre- rescue $\mathrm{HbA}_{1 \mathrm{c}}$ level carried forward. Changes in $\mathrm{HbA}_{1 \mathrm{c}}$ from baseline to week 52 in the ITT population were analysed using an ANCOVA model, with treatment group, region, history of myocardial infarction, age category ( $<65$ vs $\geq 65$ years) and current diabetes therapy (metformin vs metformin $+\mathrm{SU}$ ) as factors, and baseline $\mathrm{HbA}_{1 \mathrm{c}}$ as a continuous covariate. The difference in least squares (LS) treatment mean and its standard error were used to estimate the treatment difference and its $95 \%$ CI. Superiority of albiglutide to insulin glargine was tested if non-inferiority was established using a two-sided $t$ test at the 0.05 significance level. FPG and weight were analysed by the same ANCOVA model as the primary endpoint. Time to hyperglycaemic rescue was assessed by Kaplan-Meier analysis and logrank tests. The proportions of patients achieving each clinically meaningful $\mathrm{HbA}_{1 \mathrm{c}}$ response were analysed by non-parametric, covariance-adjusted extended Mantel-Haenszel tests. AEs were analysed by incidence proportion and incidence density rate overall and before rescue.

Study ethics The study protocol, protocol amendments and any other protocol-specific documents were reviewed and approved by the governing ethics committee or institutional review board before the study was begun. All patients provided informed written consent before participating in the trial. The study (NCT00838916) was conducted in accordance with the International Conference on Harmonisation of Technical Requirements for Registration of Pharmaceuticals for Human Use Guideline for Good Clinical Practice and the Declaration of Helsinki (as revised in 2008).

\section{Results}

Patient disposition The study was conducted at 222 centres in four countries (USA, 206 sites; Russia, 3 sites; South Africa, 12 sites; UK, 1 site) between 17 February 2009 and 8 March 2013. Of 1,060 patients screened, 779 were randomised to albiglutide $(n=516)$ or insulin glargine $(n=263)$, and 504 and 241 patients, respectively, comprised the safety population. A total of 397 ( $78.8 \%$ of the safety population) patients in the albiglutide arm and 202 (83.8\%) patients in the insulin glargine arm completed at least 52 weeks of the study. A detailed flow diagram of patient disposition is presented in Fig. 1. Baseline demographic and diabetes characteristics were similar between the safety populations of the two treatment groups (Table 1).

By week 52, the mean \pm SD dose of insulin glargine had increased from 10.1 $\pm 3.0 \mathrm{U}$ (median 10.0 U, range 2-40 U) at baseline to $35.1 \pm 25.6 \mathrm{U}$ (median $30.0 \mathrm{U}$, range 3-230 U). In the albiglutide group, $67.1 \%$ of the patients had uptitrated from 30 to $50 \mathrm{mg}$ by week 48 . The average albiglutide dose at week 48 was $43.4 \mathrm{mg}$. 
Fig. 1 Flow diagram of patient disposition up to week 52

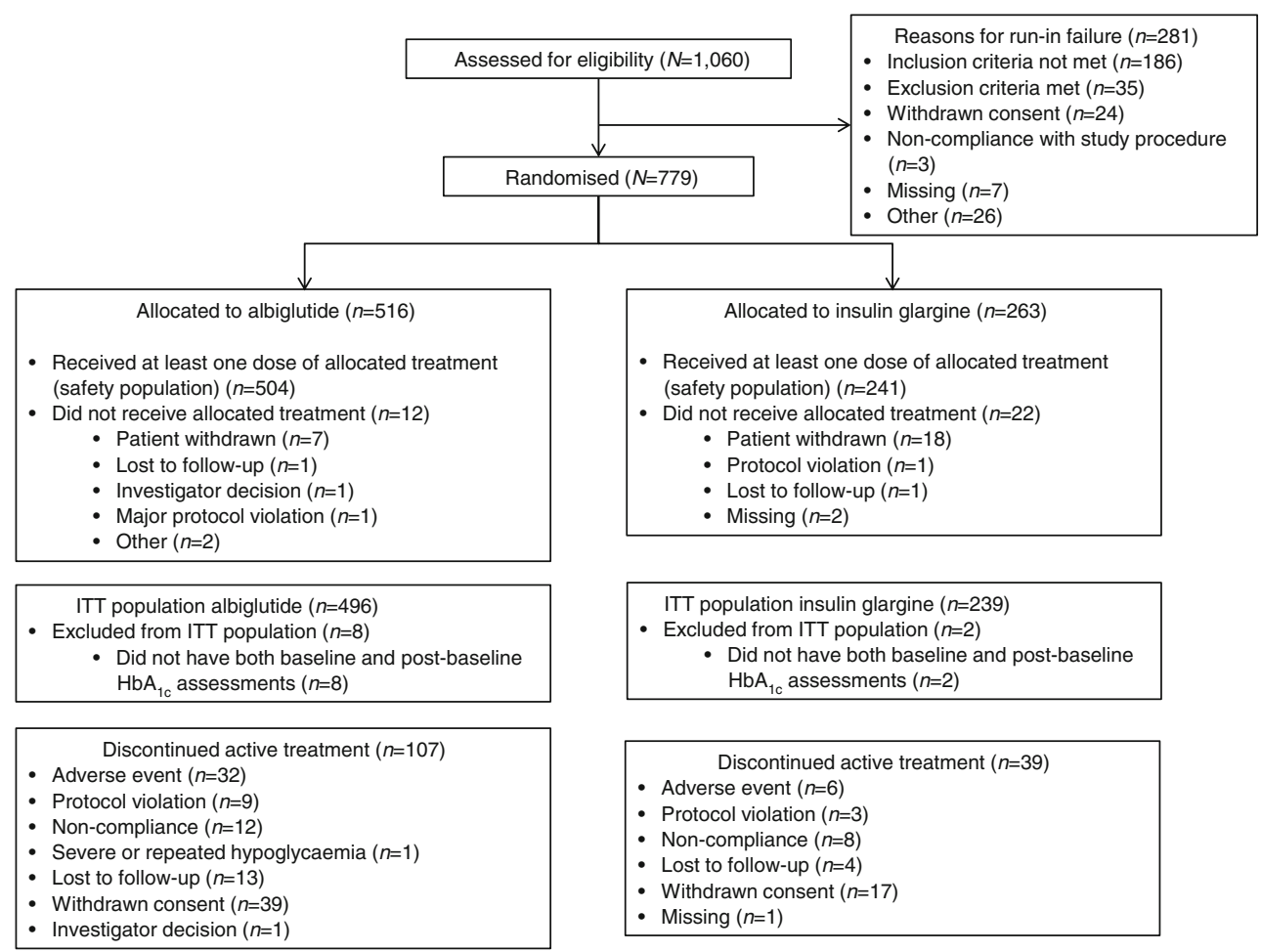

$H b A_{1 c}$ In the ITT population, $\mathrm{HbA}_{1 \mathrm{c}}$ had decreased from $8.28 \% \pm 0.90 \%(67.0 \pm 9.8 \mathrm{mmol} / \mathrm{mol})$ at baseline to $7.62 \% \pm$ $1.12 \%(59.8 \pm 12.2 \mathrm{mmol} / \mathrm{mol})$ at week 52 in the albiglutide group and from $8.36 \% \pm 0.95 \%(67.9 \pm 10.4 \mathrm{mmol} / \mathrm{mol})$ to $7.55 \% \pm 1.04 \%(59.0 \pm 11.4 \mathrm{mmol} / \mathrm{mol})$ in the insulin glargine group (Fig. 2a). The model-adjusted change from baseline to week 52 was $-0.67 \%(-7.3 \mathrm{mmol} / \mathrm{mol})$ in the albiglutide group and $-0.79 \%(-8.6 \mathrm{mmol} / \mathrm{mol})$ in the insulin glargine group (Fig. 2b). This treatment difference of $0.11 \%$ (95\% CI $-0.04 \%, 0.27 \%)(1.2 \mathrm{mmol} / \mathrm{mol}[95 \% \mathrm{CI}-0.4,3.0 \mathrm{mmol} /$ $\mathrm{mol}]$ ) met the prespecified non-inferiority margin of $0.3 \%$ (3.3 $\mathrm{mmol} / \mathrm{mol})$, indicating non-inferiority of albiglutide to insulin glargine $(p=0.0086)$. The magnitude of the response in the albiglutide group was not significantly different from that observed in the insulin glargine group $(p=0.146)$.

At week 52, a similar proportion of patients in each treatment group had achieved $\mathrm{HbA}_{1 \mathrm{c}}$ goals of $<6.5 \%$ $(<47.5 \mathrm{mmol} / \mathrm{mol})(11.0 \%$ and $10.5 \%$, albiglutide and insulin glargine, respectively), $<7.0 \%(<53.0 \mathrm{mmol} / \mathrm{mol})(31.6 \%$ and $32.8 \%)$ and $<7.5 \%(<58.5 \mathrm{mmol} / \mathrm{mol})(54.4 \%$ and $56.7 \%)$.

FPG The effect of treatment on FPG in the ITT population is presented in Fig. 2c. At week 52, FPG had declined by a mean $0.87 \mathrm{mmol} / 1(15.7 \mathrm{mg} / \mathrm{dl})$ in the albiglutide group and by $2.06 \mathrm{mmol} / \mathrm{l}(37.1 \mathrm{mg} / \mathrm{dl})$ in the insulin glargine group; the treatment difference was significant in favour of insulin glargine (Fig. 2d, $p<0.0001$ ).
Time to hyperglycaemic rescue On the basis of the KaplanMeier model, a similar proportion of patients in each group received hyperglycaemic rescue medication up to week 52 (25.6\% [albiglutide group] and 23.8\% [insulin glargine group]) (ESM Fig. 1). At week 52, the most common rescue medication in both treatment groups was insulin glargine $(9.5 \%$, albiglutide group; $11.2 \%$, insulin glargine group).

Body weight At week 52, mean body weight in the albiglutide group had declined from baseline by $1.06 \pm 3.80 \mathrm{~kg}$ and increased in the insulin glargine group by $1.57 \pm 3.81 \mathrm{~kg}$ (Fig. 3a). The model-adjusted difference in LS mean was $-2.61 \mathrm{~kg}$ (Fig. 3b; 95\% CI $-3.20,-2.02 ; p<0.0001$ ).

Albiglutide population pharmacokinetics Pre-dose plasma albiglutide concentrations at weeks 8 and 24 were $1,643 \pm 893 \mathrm{ng} / \mathrm{ml}$ and 2,159 $\pm 1,212 \mathrm{ng} / \mathrm{ml}$, respectively. Post-dose plasma albiglutide concentrations were 1,911 $\pm 966 \mathrm{ng} / \mathrm{ml}$ and $2,748 \pm 1,504 \mathrm{ng} / \mathrm{ml}$, respectively. These data are being combined with data collected from three other phase 3 studies for calculation of population pharmacokinetic variables and will be reported separately.

Safety For overall safety (i.e. including data both before and after rescue therapy), there was a higher incidence of treatment-emergent AEs to week 52 in the albiglutide group 
Table 1 Baseline demographic and diabetes characteristics of the safety population

\begin{tabular}{|c|c|c|c|c|}
\hline Characteristic & Albiglutide $(n=504)$ & Insulin glargine $(n=241)$ & Total $(N=745)$ & $p$ value \\
\hline Age (years) & $55.8 \pm 9.3$ & $54.7 \pm 9.8$ & $55.5 \pm 9.5$ & 0.147 \\
\hline$<65$ & $424(84.1)$ & $202(83.8)$ & $626(84.0)$ & 0.914 \\
\hline$\geq 65$ & $80(15.9)$ & $39(16.2)$ & $119(16.0)$ & \\
\hline \multicolumn{5}{|l|}{ Sex } \\
\hline Female & $218(43.3)$ & $109(45.2)$ & $327(43.9)$ & 0.612 \\
\hline Male & $286(56.7)$ & $132(54.8)$ & $418(56.1)$ & \\
\hline \multicolumn{5}{|l|}{ Race } \\
\hline African-American/African & $130(25.8)$ & $64(26.6)$ & $194(26.0)$ & \\
\hline American-Indian or Alaskan Native & $3(0.6)$ & $1(0.4)$ & $4(0.5)$ & \\
\hline Native Hawaiian or other Pacific Islander & $1(0.2)$ & 0 & $1(0.1)$ & \\
\hline White (white/European heritage) & $342(67.9)$ & $158(65.6)$ & $500(67.1)$ & \\
\hline White (Arabic/North African heritage) & $7(1.4)$ & $2(0.8)$ & $9(1.2)$ & \\
\hline Asian (Central/South Asian heritage) & $7(1.4)$ & $5(2.1)$ & $12(1.6)$ & \\
\hline Asian (East Asian heritage) & $2(0.4)$ & $1(0.4)$ & $3(0.4)$ & \\
\hline Asian (Japanese heritage) & 0 & $1(0.4)$ & $1(0.1)$ & \\
\hline Asian (Southeast Asian) & $16(3.2)$ & $8(3.3)$ & $24(3.2)$ & \\
\hline Other & $2(0.4)$ & $1(0.4)$ & $3(0.4)$ & \\
\hline \multicolumn{5}{|l|}{ Ethnicity } \\
\hline Hispanic/Latino & $81(16.1)$ & $38(15.8)$ & $119(16.0)$ & 0.916 \\
\hline Not Hispanic/Latino & $423(83.9)$ & $203(84.2)$ & $626(84.0)$ & \\
\hline Weight (kg) & $95.1 \pm 19.7$ & $94.6 \pm 19.1$ & $94.9 \pm 19.5$ & 0.729 \\
\hline BMI $\left(\mathrm{kg} / \mathrm{m}^{2}\right)$ & $33.2 \pm 5.6$ & $33.0 \pm 5.4$ & $33.1 \pm 5.5$ & 0.652 \\
\hline \multicolumn{5}{|l|}{ BMI category } \\
\hline$<25 \mathrm{~kg} / \mathrm{m}^{2}$ & $26(5.2)$ & $8(3.3)$ & $34(4.6)$ & 0.310 \\
\hline$\geq 25$ to $<30 \mathrm{~kg} / \mathrm{m}^{2}$ & $116(23.0)$ & $63(26.1)$ & $179(24.0)$ & \\
\hline$\geq 30$ to $<35 \mathrm{~kg} / \mathrm{m}^{2}$ & $155(30.8)$ & $83(34.4)$ & $238(31.9)$ & \\
\hline$\geq 35 \mathrm{~kg} / \mathrm{m}^{2}$ & $207(41.1)$ & $87(36.1)$ & $294(39.5)$ & \\
\hline Duration of diabetes (years) & $8.9 \pm 6.5$ & $8.4 \pm 5.7$ & $8.8 \pm 6.3$ & 0.322 \\
\hline \multicolumn{5}{|l|}{ Current glucose-lowering therapy } \\
\hline Metformin alone & $91(18.1)$ & $44(18.3)$ & $135(18.1)$ & 0.927 \\
\hline Metformin $+\mathrm{SU}$ & $413(81.9)$ & $196(81.7)$ & $609(81.9)$ & \\
\hline \multicolumn{5}{|l|}{ Baseline $\mathrm{HbA}_{1 \mathrm{c}}$} \\
\hline$\%$ & $8.28 \pm 0.90$ & $8.36 \pm 0.95$ & $8.31 \pm 0.92$ & 0.229 \\
\hline $\mathrm{mmol} / \mathrm{mol}$ & $67.0 \pm 9.8$ & $67.9 \pm 10.4$ & $67.3 \pm 10.1$ & \\
\hline \multicolumn{5}{|l|}{ Baseline FPG } \\
\hline $\mathrm{mmol} / 1$ & $9.4 \pm 2.8$ & $9.7 \pm 2.9$ & & \\
\hline $\mathrm{mg} / \mathrm{dl}$ & $169.4 \pm 51.0$ & $175.1 \pm 53.4$ & & \\
\hline Prior myocardial infarction & $26(5.2)$ & $11(4.6)$ & $37(5.0)$ & 0.727 \\
\hline
\end{tabular}

Values are mean $\pm \mathrm{SD}$ or $n(\%)$

than in the insulin glargine group, whereas the incidence of SAEs was similar in both treatment groups (Table 2). Treatment-related AEs occurred with higher frequency in the albiglutide group primarily because of a higher incidence of injection-site reactions (ISRs) and gastrointestinal AEs. More albiglutide-treated patients than those treated with insulin glargine withdrew from the study because of an AE (Table 2). The most common AE leading to withdrawal in the albiglutide group was ISR $(1.8 \%)$ followed by nausea $(0.8 \%)$. Nausea occurred in more albiglutide-treated patients $(9.9 \%)$ than insulin glargine-treated patients (3.7\%) (Table 2), although the incidence of vomiting was similar in the two groups $(3.8 \%$ and $3.7 \%$, respectively). Six deaths occurred during the study to week 52 (three in each group), but none were deemed to be related to study treatment by the investigator. The incidence rates of AEs occurring before receiving hyperglycaemic 
a

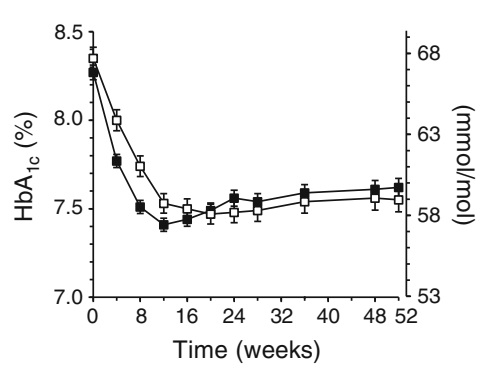

b

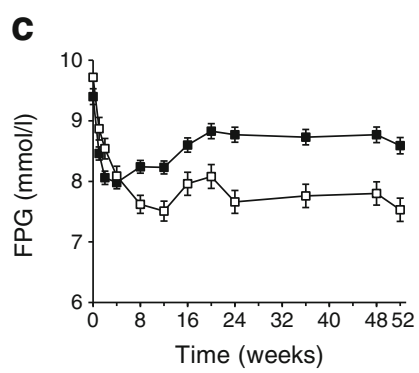

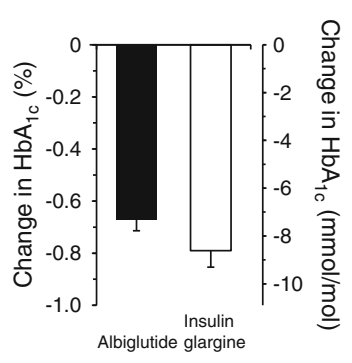

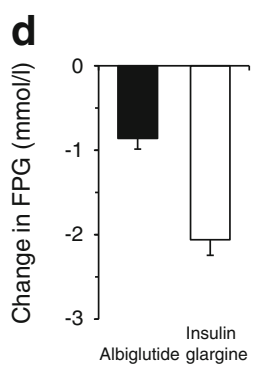

Fig. 2 Effect of albiglutide and insulin glargine treatment on $\mathrm{HbA}_{1 \mathrm{c}}(\mathbf{a}$, b) and FPG (c, d) in the ITT population to week 52. (a) $\mathrm{HbA}_{1 \mathrm{c}}$ (mean \pm SE) during treatment with albiglutide (black squares, $n=496$ ) or insulin glargine (white squares, $n=239$ ). (b) The model-adjusted change in $\mathrm{HbA}_{1 \mathrm{c}}$ (LS mean $\pm \mathrm{SE}$ ) from baseline to week 52 . Factors were treatment, baseline $\mathrm{HbA}_{1 \mathrm{c}}$, prior myocardial infarction history, age category, region and current glucose-lowering therapy. The analysis used LOCF for missing values. The LS mean change was not significantly different between the two treatment groups $(p=0.146)$. The non-inferiority $p$ value for $\mathrm{HbA}_{1 \mathrm{c}}$ change from baseline was 0.0086. (c) FPG (mean \pm SE) during treatment with albiglutide (black squares, $n=496$ ) or insulin glargine (whites squares, $n=239$ ). (d) The model-adjusted change in FPG (LS mean $\pm \mathrm{SE}$ ) from baseline to week 52 . The factors were the same as in (b). The model used LOCF for missing values. The LS mean change was significantly different between treatment groups $(p<0.0001)$

rescue therapy were similar to the overall rate up to week 52 (80.2\% and $73.4 \%$ for albiglutide and insulin glargine, respectively; ESM Table 4).
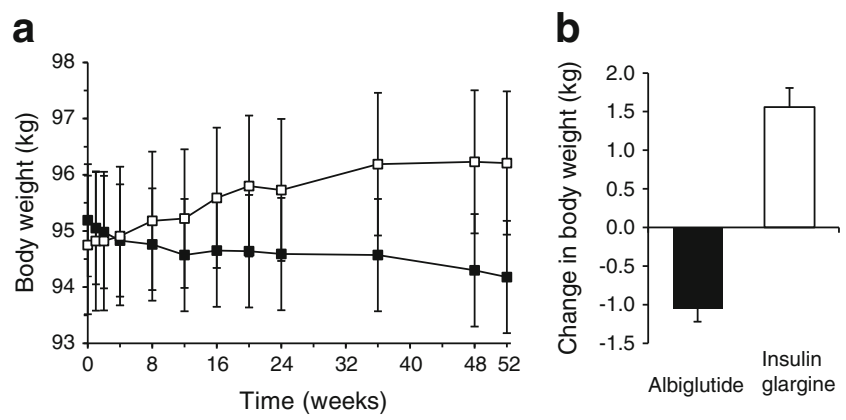

Fig. 3 Effect of treatment on body weight in the ITT population to week 52. (a) Body weight (mean \pm SE) during treatment with albiglutide (black squares, $n=496$ ) or insulin glargine (white squares, $n=239$ ). (b) Change in LS mean $( \pm \mathrm{SE})$ body weight from baseline to week 52 . Factors were treatment, baseline $\mathrm{HbA}_{1 \mathrm{c}}$, prior myocardial infarction history, age category, region and current glucose-lowering therapy. The analysis used LOCF for missing values. The difference in LS mean change in body weight between treatment groups was significant $(p<0.0001)$

ISRS The incidence of investigator-identified ISRs (includes more than one event descriptor, e.g. 'injection-site reaction', 'injection-site pruritus', etc.) to week 52 was greater in the albiglutide group ( $n=70$ patients, $13.9 \%$ ) than in the insulin glargine group ( $n=21$ patients, $8.7 \%$ ). ISRs in the albiglutide group were typically characterised by localised redness and itching, whereas ISRs in the insulin glargine group were mostly associated with other symptoms and redness. Nearly all were mild or moderate in severity $(99.0 \%$ in the albiglutide group and $100 \%$ in the insulin glargine group). Most patients reporting ISRs had only one or two events up to week 52 (62\% in the albiglutide group and $77 \%$ in the insulin glargine group). Median duration of the ISR was 6.0 days in the albiglutide group and 8.0 days in the insulin glargine group. During the first 52 weeks of the study, 12 patients in the albiglutide group withdrew because of investigator-identified ISRs vs no patients in the insulin glargine group.

Hypoglycaemia Documented symptomatic hypoglycaemia was experienced by $17.5 \%$ of patients in the albiglutide group and by $27.4 \%$ of patients in the insulin glargine group before receiving hyperglycaemic rescue therapy up to week 52 (Table 3). The model-adjusted incidence rate was higher in the insulin glargine group (108.8 events per 100 person-years) than in the albiglutide group (61.4 events per 100 personyears; $p=0.0377$ ). Most pre-rescue hypoglycaemia events in both groups occurred in patients taking metformin $+\mathrm{SU}$ as background medication (Table 3). Two episodes of severe hypoglycaemia occurred in each treatment group; all were in patients treated with metformin + SU. No patient withdrew from the study because of hypoglycaemia.

Pancreatitis, thyroid cancer and potential systemic allergic reactions No pancreatitis was observed in the albiglutide group. One case of suspected pancreatitis (verbatim term 'ascites') in the insulin glargine group was evaluated by the PAC during the first 52 weeks of the study and was adjudicated as 'not likely' to be pancreatitis. The patient remained in the study.

No patients developed thyroid cancer. Median calcitonin levels were similar between albiglutide and insulin glargine groups at baseline and did not change by week 52 (median= $2.0 \mathrm{pg} / \mathrm{ml}$ at both time points in both groups).

No cases of angioedema or anaphylaxis occurred up to week 52 .

Plasma lipid profiles, blood pressure and heart rate At baseline, the mean serum concentrations of LDL-cholesterol, HDL-cholesterol, total cholesterol and triacylglycerols were similar in the two treatment groups (ESM Table 5). Both groups showed similar, small reductions in LDL-cholesterol, total cholesterol and triacylglycerols and a small increase in HDL-cholesterol at week 52 (ESM Table 5). 
Table 2 Treatment-emergent AEs occurring in $>5 \%$ of the patients in the safety population in either treatment group to week 52

\begin{tabular}{|c|c|c|c|c|}
\hline \multirow[t]{2}{*}{$\mathrm{AE}$} & \multicolumn{2}{|c|}{ Albiglutide $(n=504)$} & \multicolumn{2}{|c|}{ Insulin glargine $(n=241)$} \\
\hline & $\begin{array}{l}\text { Patients } \\
n(\%)\end{array}$ & $\begin{array}{l}\text { Events } \\
n\left(\text { rate }^{\mathrm{a}}\right)\end{array}$ & $\begin{array}{l}\text { Patients } \\
n(\%)\end{array}$ & $\begin{array}{l}\text { Events } \\
n\left(\text { rate }^{\mathrm{a}}\right)\end{array}$ \\
\hline Any AE & $412(81.7)$ & $1,895(372.7)$ & $181(75.1)$ & $799(319.1)$ \\
\hline Any serious $\mathrm{AE}$ & $42(8.3)$ & $50(9.8)$ & $20(8.3)$ & $23(9.2)$ \\
\hline Treatment-related AEs & $140(27.8)$ & $474(93.2)$ & $32(13.3)$ & $74(29.6)$ \\
\hline AEs leading to withdrawal & $35(6.9)$ & $35(6.9)$ & $6(2.5)$ & $6(2.4)$ \\
\hline \multicolumn{5}{|l|}{ Most common AEs up to week 52} \\
\hline Nausea & $50(9.9)$ & $81(15.9)$ & $9(3.7)$ & $10(4.0)$ \\
\hline Upper respiratory tract infection & $46(9.1)$ & $50(9.8)$ & $24(10.0)$ & $33(13.2)$ \\
\hline ISR & $43(8.5)$ & $220(43.3)$ & $6(2.5)$ & $8(3.2)$ \\
\hline Diarrhoea & $38(7.5)$ & $46(9.1)$ & $10(4.1)$ & $13(5.2)$ \\
\hline Nasopharyngitis & $32(6.3)$ & $38(7.5)$ & $10(4.1)$ & $15(6.0)$ \\
\hline Headache & $31(6.2)$ & $36(7.1)$ & $17(7.1)$ & $19(7.6)$ \\
\hline Hypertension & $31(6.2)$ & $31(6.1)$ & $17(7.1)$ & $17(6.8)$ \\
\hline Urinary tract infection & $30(6.0)$ & $35(6.9)$ & $11(4.6)$ & $17(6.8)$ \\
\hline Sinusitis & $29(5.8)$ & $35(6.9)$ & $17(7.1)$ & $22(8.8)$ \\
\hline Cough & $27(5.4)$ & $29(5.7)$ & $22(9.1)$ & $26(10.4)$ \\
\hline Influenza & $26(5.2)$ & $30(5.9)$ & $15(6.2)$ & $19(7.6)$ \\
\hline Bronchitis & $21(4.2)$ & $24(4.7)$ & $16(6.6)$ & $17(6.8)$ \\
\hline Injection-site haematoma & $16(3.2)$ & $20(3.9)$ & $19(7.9)$ & $28(11.2)$ \\
\hline
\end{tabular}

${ }^{a}$ Event rate per 100 patient-years

Table 3 Pre-rescue hypoglycaemic events in the safety population to week 52

\begin{tabular}{|c|c|c|c|c|}
\hline \multirow[t]{2}{*}{ Glucose-lowering medication } & \multicolumn{2}{|c|}{ Albiglutide $(n=504)$} & \multicolumn{2}{|c|}{ Insulin glargine $(n=241)$} \\
\hline & $\begin{array}{l}\text { Patients } \\
n(\%)\end{array}$ & $\begin{array}{l}\text { Events } \\
\left.n \text { (rate }^{\mathrm{a}}\right)\end{array}$ & $\begin{array}{l}\text { Patients } \\
n(\%)\end{array}$ & $\begin{array}{l}\text { Events } \\
n\left(\text { rate }^{\mathrm{a}}\right)\end{array}$ \\
\hline \multicolumn{5}{|l|}{ Overall } \\
\hline Any hypoglycaemic event & $127(25.2)$ & $411(89.1)$ & $89(36.9)$ & $360(160.0)$ \\
\hline Documented symptomatic ${ }^{b}$ & $88(17.5)$ & 281 & $66(27.4)$ & 259 \\
\hline Asymptomatic $^{c}$ & $32(6.3)$ & 51 & $25(10.4)$ & 42 \\
\hline Severe $^{\mathrm{d}}$ & $2(0.4)$ & 2 & $1(0.4)$ & 2 \\
\hline Metformin alone & $n=91$ & & $n=44$ & \\
\hline Any hypoglycaemic event & $4(4.4)$ & $9(11.5)$ & $10(22.7)$ & $18(42.8)$ \\
\hline Documented symptomatic ${ }^{\mathrm{b}}$ & $1(1.1)$ & 1 & $8(18.2)$ & 14 \\
\hline Asymptomatic ${ }^{c}$ & $2(2.2)$ & 2 & $1(2.3)$ & 1 \\
\hline Severe $^{\mathrm{d}}$ & 0 & 0 & 0 & 0 \\
\hline Metformin $+\mathrm{SU}$ & $n=413$ & & $n=196$ & \\
\hline Any hypoglycaemic event & $123(29.8)$ & $402(105.0)$ & $79(40.3)$ & $342(187.1)$ \\
\hline Documented symptomatic ${ }^{\mathrm{b}}$ & $87(21.1)$ & 280 & $58(29.6)$ & 245 \\
\hline Asymptomatic $^{c}$ & $30(7.3)$ & 49 & $24(12.2)$ & 41 \\
\hline Severe $^{\mathrm{d}}$ & $2(0.5)$ & 2 & $1(0.5)$ & 2 \\
\hline
\end{tabular}

${ }^{\mathrm{a}}$ Event rate per 100 patient-years

${ }^{\mathrm{b}}$ Plasma glucose $\leq 3.9 \mathrm{mmol} / \mathrm{l}(70 \mathrm{mg} / \mathrm{dl})$ and presence of hypoglycaemic symptoms

${ }^{\mathrm{c}}$ Plasma glucose $\leq 3.9 \mathrm{mmol} / \mathrm{l}(70 \mathrm{mg} / \mathrm{dl})$ and absence of hypoglycaemic symptoms

${ }^{\mathrm{d}}$ Event requiring another person to administer a resuscitative action 
At week 52, mean systolic blood pressure had decreased from $130.3 \pm 14.0$ by $1.4 \pm 14.4 \mathrm{mmHg}$ in the albiglutide group and increased by $0.3 \pm 13.7 \mathrm{mmHg}$ from $131.6 \pm 14.0 \mathrm{mmHg}$ in the insulin glargine group (ESM Table 5). Diastolic blood pressure had decreased in both groups at week 52 (by $-0.8 \pm$ 10.0 and $-1.8 \pm 8.8 \mathrm{mmHg}$ for albiglutide and insulin glargine, respectively). At week 52, heart rate had increased in the albiglutide group by $1.0 \pm 8.5$ beats $/ \mathrm{min}$ from $73.4 \pm 10.2$ beats/min at baseline. No change in mean heart rate was observed in the insulin glargine group.

\section{Discussion}

The results of this study show that weekly albiglutide controlled hyperglycaemia up to week 52 in patients with type 2 diabetes who were inadequately controlled on metformin alone or metformin $+\mathrm{SU}$. The primary efficacy endpoint of change in $\mathrm{HbA}_{1 \mathrm{c}}$ from baseline shows that albiglutide was non-inferior to insulin glargine in this patient population. A significant difference between treatments was observed for effect on body weight, with albiglutide being associated with weight loss compared with insulin glargine, which was associated with weight gain. Albiglutide was associated with a significantly lower risk of hypoglycaemia than insulin glargine. The most common AEs in the albiglutide group were nausea and ISRs, both of which occurred at higher rates than in the insulin glargine group and led to a two-threefold higher $\mathrm{AE}$ withdrawal rate in the albiglutide group.

This study used several design features that warrant highlighting. First, in the albiglutide group, uptitration of the dose was based on the glycaemic response of individual patients and did not occur at a prespecified (or forced) time point of the study. Therefore, the safety and efficacy responses of albiglutide reflect the pooled analysis of both the 30 and $50 \mathrm{mg}$ doses. Second, the study protocol specified that hyperglycaemic rescue medication was to be used and that the patients who received rescue medication were to remain in the study on randomised study medication. It is important to note that only pre-rescue results were included in the efficacy assessments, but the safety assessment included both the preand post-rescue periods, allowing a longer period of exposure to the study medication and a longer assessment of safety. Because many type 2 diabetes treatment regimens require dose adjustments and/or additional medications, the results of this study reflect a 'real world' use of albiglutide and insulin glargine.

The efficacy results of this study with a 52 week endpoint are similar to shorter duration clinical studies with other GLP1 receptor agonists compared with basal insulin in the treatment of type 2 diabetes in patients who were inadequately controlled with combination therapy of metformin + SU.
Although limitations exist when comparing results from different clinical trials, the addition of exenatide (titrated to $10 \mu \mathrm{g}$ twice daily) or insulin glargine (once daily titrated to achieve an FPG $<5.6 \mathrm{mmol} / 1[100 \mathrm{mg} / \mathrm{dl}])$ to treatment regimens of patients with type 2 diabetes produced equivalent reductions in $\mathrm{HbA}_{1 \mathrm{c}}(-1.11 \%[-12.1 \mathrm{mmol} / \mathrm{mol}]$ in each group) after 26 weeks [12]. Similarly, 26 weeks of treatment with liraglutide (titrated to $1.8 \mathrm{mg}$ once daily) or insulin glargine (once daily titrated to achieve an FPG $\leq 5.5 \mathrm{mmol} / 1$ [99 mg/dl]) reduced $\mathrm{HbA}_{1 \mathrm{c}}$ by $1.33 \%(14.5 \mathrm{mmol} / \mathrm{mol})$ and $1.09 \%$ $(11.9 \mathrm{mmol} / \mathrm{mol})$, respectively $(p=0.0015)$ [13].

When assessing the FPG data in the two arms of the present study, one must consider that insulin glargine dose adjustments were made frequently based on FPG levels, whereas in the albiglutide arm, there was only one dose increase (if required) during the study. Both FPG and postprandial glucose levels contribute to the overall glycaemic lowering effect (i.e. $\mathrm{HbA}_{1 \mathrm{c}}$ levels). While postprandial glucose was not assessed in the present study, previous data using a standardised mixed-meal tolerance test showed that albiglutide had effects on both fasting and postprandial glucose [14].

Fear of hypoglycaemia and the potential for weight gain are two barriers to patient acceptance of insulin therapy in type 2 diabetes $[5,6,15]$. Even minor hypoglycaemic episodes may lead to a reduction in compliance with insulin therapy [5]. In the present study, there were fewer documented symptomatic and severe hypoglycaemic events in the albiglutide group than in the insulin glargine group, and albiglutide-treated patients demonstrated body weight loss, whereas weight gain was seen in the insulin glargine group. These favourable characteristics suggest that albiglutide may be an alternative choice to insulin glargine in patients who require an injectable antihyperglycaemic agent to control blood glucose.

The 1 year incidence of gastrointestinal AEs (specifically nausea, vomiting and diarrhoea) of weekly albiglutide in the present study is lower than that reported for liraglutide [16, 17] and lower or similar to shorter duration studies with onceweekly exenatide $[18,19]$. Weekly dosing with GLP-1 agonists generally appears to reduce the incidence rates of these gastrointestinal AEs compared with daily or twice-daily dosing as demonstrated in two studies of $2.0 \mathrm{mg}$ exenatide once weekly compared with $10.0 \mu \mathrm{g}$ exenatide twice daily [20,21] and in a study of $2.0 \mathrm{mg}$ exenatide once weekly vs $1.8 \mathrm{mg}$ liraglutide once daily [19]. The relatively low incidence rates of these gastrointestinal AEs in the present study may be an important predictor of treatment adherence. A recent study of pharmacy records of $>50,000$ patients who initiated treatment with twice-daily exenatide and $>1,500$ patients who initiated liraglutide between 2005 and 2010 found that annual adherence with treatment was low (20\% for exenatide and $31 \%$ for liraglutide in 2010) and that medically treated nausea or 
vomiting were significantly associated with non-adherence to exenatide [22].

Although metformin remains the preferred initial drug of choice for treatment of newly diagnosed type 2 diabetes, current treatment guidelines do not specify which class of glucose-lowering medication should be added in patients who are inadequately controlled with metformin alone [2, $23,24]$. GLP-1 receptor agonists are one of the classes that should be considered as add-on therapy in those patients in whom metformin alone or in combination with another oral agent is inadequate for hyperglycaemic control [2, 23, 24]. In addition to their ability to reduce $\mathrm{HbA}_{1 \mathrm{c}}$, the GLP-1 receptor agonists are associated with modest loss of body weight [25], which may be considered an advantage compared with the weight gain that is often seen with insulin therapy. In addition, the convenience of weekly dosing with albiglutide compared with daily dosing with insulin glargine may be preferred by patients.

This study has several limitations. Because of the comparison with insulin glargine, the study design was open-label. The uptitration of the albiglutide dose at various times during the study complicates the interpretation of the efficacy and safety results because patients treated with either 30 or $50 \mathrm{mg}$ were pooled for these analyses. The study design was meant to reproduce a 'real world' clinical approach, and the decision was made not to use a treat-to-target paradigm, in which a Glucose Monitoring Committee directed the insulin glargine dose for individual patients. As such, the titration of insulin glargine was outlined in the protocol, and individual decisions on insulin glargine dose adjustment were made by the study investigators. Our study findings in the insulin glargine arm are consistent with other 'real world' trials that did not use a treat-to-target design [26].

In conclusion, albiglutide was effective in lowering blood glucose as shown by the significant reduction in $\mathrm{HbA}_{1 \mathrm{c}}$ in patients with type 2 diabetes who were not well controlled on a regimen of metformin alone or in combination with SU. The $\mathrm{HbA}_{1 \mathrm{c}}$-lowering response of albiglutide was non-inferior to insulin glargine and occurred without the weight gain and increased hypoglycaemic risk observed in the insulin glargine group. These results suggest that weekly albiglutide may be considered as an alternative to daily insulin glargine for addon therapy in this patient population.

Acknowledgements The authors thank D. L. Wicks of GlaxoSmithKline for management of manuscript development. Editorial support was provided by E. Weselcouch of PharmaWrite (assistance with the production of draft outline, production of manuscript first draft, assembling tables and figures, and collating author comments), D. Talag of PharmaWrite (assistance with copyediting and fact checking) and S. Cambareri of PharmaWrite (art direction), which was funded by GlaxoSmithKline. A poster describing the results of this study was presented at the American Diabetes Association 73rd Scientific Sessions, 21-25 June 2013, Chicago, IL [27] and also at the 49th Annual Meeting of the European Association for the Study of Diabetes, 23-27 September 2013, Barcelona, Spain [28].

Funding This study was planned and conducted by GlaxoSmithKline. Professional medical writing was paid for by GlaxoSmithKline and was provided by PharmaWrite (Princeton, NJ, USA).

Duality of interest PNW received research grants and speaking honoraria from GlaxoSmithKline. RP served as a consultant or speaker, and/or received grants/research support or honoraria from Novartis, Lilly, Eisai, Takeda, Novo Nordisk, Merck, Mannkind, AstraZeneca/Bristol-Myers Squibb, Roche, Sanofi-Aventis, GlaxoSmithKline, Pfizer and Lexicon. All honoraria from these activities are directed to a non-profit foundation. MCC, JY, DTC, MS and CP are employed by and are shareholders of GlaxoSmithKline.

Contribution statement PNW provided study patients. PNW, MCC, JY, DTC, MS, CP and RP were responsible for data analysis and interpretation. PNW, MCC, JY, DTC, MS, CP and RP wrote and were critically involved in revising the manuscript. JY was responsible for the statistical analysis. All authors reviewed the final manuscript and gave approval for submission. PNW is the guarantor of this work.

\section{References}

1. Turner RC, Cull CA, Frighi V, Holman RR (1999) Glycemic control with diet, sulfonylurea, metformin, or insulin in patients with type 2 diabetes mellitus: progressive requirement for multiple therapies (UKPDS 49). JAMA 281:2005-2012

2. Inzucchi SE, Bergenstal RM, Buse JB et al (2012) Management of hyperglycemia in type 2 diabetes: a patient-centered approach. Position statement of the American Diabetes Association (ADA) and the European Association for the Study of Diabetes (EASD). Diabetes Care 35:1364-1379

3. Dailey G, Admane K, Mercier F, Owens D (2010) Relationship of insulin dose, alc lowering, and weight in type 2 diabetes: comparing insulin glargine and insulin detemir. Diabetes Technol Ther 12:1019-1027

4. Little S, Shaw J, Home P (2011) Hypoglycemia rates with basal insulin analogs. Diabetes Technol Ther 13(Suppl 1):S53-S64

5. Unger J (2012) Uncovering undetected hypoglycemic events. Diabetes Metab Syndr Obes 5:57-74

6. Russell-Jones D, Khan R (2007) Insulin-associated weight gain in diabetes: causes, effects and coping strategies. Diabetes Obes Metab 9:799-812

7. Drucker DJ, Nauck MA (2006) The incretin system: glucagon-like peptide-1 receptor agonists and dipeptidyl peptidase-4 inhibitors in type 2 diabetes. Lancet 368:1696-1705

8. Garber AJ (2011) Long-acting glucagon-like peptide 1 receptor agonists: a review of their efficacy and tolerability. Diabetes Care 34(Suppl 2):S279-S284

9. Bush MA, Matthews JE, De Boever EH et al (2009) Safety, tolerability, pharmacodynamics and pharmacokinetics of albiglutide, a long-acting glucagon-like peptide-1 mimetic, in healthy subjects. Diabetes Obes Metab 11:498-505

10. Matthews JE, Stewart MW, De Boever EH et al (2008) Pharmacodynamics, pharmacokinetics, safety and tolerability of albiglutide, a long-acting GLP-1 mimetic, in patients with type 2 diabetes. J Clin Endocrinol Metab 93:4810-4817

11. American Diabetes Association Workgroup on Hypoglycemia (2005) Defining and reporting hypoglycemia in diabetes: a report from the American Diabetes Association. Diabetes Care 28:1245-1249 
12. Heine RJ, Van Gaal LF, Johns D, Mihm MJ, Widel MH, Brodows RG (2005) Exenatide versus insulin glargine in patients with suboptimally controlled type 2 diabetes: a randomized trial. Ann Intern Med 143:559-569

13. Russell-Jones D, Vaag A, Schmitz O et al (2009) Liraglutide vs insulin glargine and placebo in combination with metformin and sulfonylurea therapy in type 2 diabetes mellitus: a randomised controlled trial (LEAD-5 met + SU). Diabetologia 52:2046-2055

14. Seino Y, Inagaki N, Miyahara $H$ et al (2014) A randomized dosefinding study demonstrating efficacy and tolerability of albiglutide in Japanese patients with type 2 diabetes mellitus. Curr Med Res Opin 30:1095-1106

15. Philis-Tsimikas A (2013) Initiating basal insulin therapy in type 2 diabetes: practical steps to optimize glycemic control. Am J Med 126:S21-S27

16. Novo Nordisk (April 2013) Victoza (liraglutide [rDNA origin] injection) [prescribing information]. Novo Nordisk, Princeton, NJ

17. Pratley RE, Nauck MA, Barnett AH et al (2014) Once-weekly albiglutide versus once-daily liraglutide in patients with type 2 diabetes inadequately controlled on oral drugs (HARMONY 7): a randomised, open-label, multicentre, non-inferiority phase 3 study. Lancet Diabetes Endocrinol 2:289-297

18. Amylin Pharmaceuticals (January 2012) Bydureon (exenatide extended-release for injectable suspension) [prescribing information]. Amylin Pharmaceuticals, San Diego, CA

19. Buse JB, Nauck M, Forst T et al (2013) Exenatide once weekly versus liraglutide once daily in patients with type 2 diabetes (DURATION-6): a randomised, open-label study. Lancet 381:117-124
20. Drucker DJ, Buse JB, Taylor K et al (2008) Exenatide once weekly versus twice daily for the treatment of type 2 diabetes: a randomised, open-label, non-inferiority study. Lancet 372:1240-1250

21. Blevins T, Pullman J, Malloy J et al (2011) DURATION-5: exenatide once weekly resulted in greater improvements in glycemic control compared with exenatide twice daily in patients with type 2 diabetes. J Clin Endocrinol Metab 96:1301-1310

22. Chou E, Wang H, Miao W, Germe M, Fournier M, Schwartz S (2012) Adherence to GLP-1 agonist therapy in U.S. managed care. Diabetes 61(Suppl 1):A314

23. American Diabetes Association (2013) Standards of medical care in diabetes-2013. Diabetes Care 36(Suppl 1):S11-S66

24. Garber AJ, Abrahamson MJ, Barzilay JI et al (2013) AACE comprehensive diabetes management algorithm 2013. Endocr Pract 19:327-336

25. Monami M, Dicembrini I, Marchionni N, Rotella CM, Mannucci E (2012) Effects of glucagon-like peptide-1 receptor agonists on body weight: a meta-analysis. Exp Diabetes Res 2012:672658

26. Heintjes EM, Thomsen TL, Penning-van Beest FJ, Christensen TE, Herings RM (2010) Glycemic control and long-acting insulin analog utilization in patients with type 2 diabetes. Adv Ther 27:211-222

27. Pratley R, Stewart M, Cirkel D, Ye J, Perry C, Carr MC (2013) HARMONY 4: 52-wk efficacy of albiglutide (Albi) vs. insulin glargine (Glar) in patients (pts) with T2DM. ADA, late breaking abstracts, available from http://professional.diabetes.org/admin/ UserFiles/combinedfile.pdf (Abstract 54-LB)

28. Pratley R, Stewart M, Cirkel D, Ye J, Perry C, Carr MC (2013) HARMONY 4: 52-week efficacy of albiglutide vs. insulin glargine in patients with type 2 diabetes mellitus. Diabetologia 56(Suppl): S360-S361 (Abstract 904) 